\title{
Evaluation of the neuromuscular compartments in the peroneus longus muscle through electrical stimulation and accelerometry*
}

\author{
Guillermo A. Méndez ${ }^{1}$, Valeska F. Gatica ${ }^{1}$, \\ Eduardo E. Guzmán ${ }^{1}$, Alex E. Soto ${ }^{2}$
}

\begin{abstract}
Background: Muscles are innervated exclusively by a nerve branch and possess definite actions. However, mammalian skeletal muscles, such as the trapezius, the medial gastrocnemius, and the peroneus longus, are compartmentalized. In the peroneus longus muscle, multiple motor points, which innervate individual neuromuscular compartments (NMC), the superior (S-NMC), anteroinferior (AI-NMC), and posteroinferior (PI-NMC), have been described. The contribution of each neuromuscular compartment to the final action of the muscle is fundamental for the rehabilitation of patients afflicted by neurological and muscle dysfunctions. Interventions are often based on electrical principles that take advantage of the physiological characteristics of muscles and nerves to generate therapeutic effects. Objective: To compare the effects of stimulating the different neuromuscular compartments (NMCs) of the peroneus longus muscle on the motor threshold (MT) and acceleration of the foot. Method: This is a cross-sectional study comprising 37 subjects. The three NMCs of the peroneus longus muscle were stimulated, and the acceleration of the foot and the motor threshold of each NMC were evaluated. A repeated measures analysis of variance with Bonferroni corrections of two intra-subjects factors was performed. Results: The stimulation of the different NMCs did not result in any differences in MT $(F=2.635, P=0.079)$. There were significant differences between the axes of acceleration caused by the stimulation of the different NMCs $(F=56,233 ; P=0.000)$. The stimulation of the posteroinferior compartment resulted in the greatest acceleration in the $\mathrm{X}$-axis (mean 0.614; standard deviation 0.253). Conclusions: The posteroinferior compartment primarily contributes to the eversion movement of the foot. NMCs have specific functional roles that contribute to the actions of the muscles to which they belong.
\end{abstract}

Keywords: neuromuscular compartment; peroneus longus muscle; accelerometry; motor threshold; motor point; physical therapy.

\section{HOW TO CITE THIS ARTICLE}

Méndez GA, Gatica VF, Guzmán EE, Soto AE. Evaluation of the neuromuscular compartments in the peroneus longus muscle through electrical stimulation and accelerometry. Braz J Phys Ther. 2013 Sept-Oct; 17(5):427-434. http://dx.doi.org/10.1590/ S1413-35552012005000110

\section{Introduction}

Conventionally, muscles have been described as possessing definite actions, with exclusive innervation by a nerve branch. However, mammalian skeletal muscles, such as the trapezius ${ }^{1}$, the extensor carpi radialis longus and brevis $^{2}$, the tibialis anterior ${ }^{3}$, the brachialis anterior $^{4}$, the long head of triceps ${ }^{5}$, the sartorius $^{6}$, the medial gastrocnemius and the soleus ${ }^{7}$, and the peroneus longus ${ }^{8}$, possess multiple actions that correlate with their muscular architecture and neural organization ${ }^{9}$. In 1974, Letbetter ${ }^{10}$ characterized the subdivisions of the medial gastrocnemius in the cat, establishing the basis for the investigation of other muscles in animals and humans. In 1982, English and Letbetter ${ }^{11}$ defined neuromuscular compartments
(NMCs) as muscle subdivisions that are innervated by unique sets of motor neurons. This organization occurs at the innervation level, particularly at the union of a nerve with a muscle. An example of this structure is the peroneus longus muscle, in which the presence of multiple motor branches has been detected, with each of them innervating a subdivision or neuromuscular compartment (NMC), specifically, the superior (S-NMC), anteroinferior (AI-NMC), and posteroinferior (PI-NMC) ${ }^{12,13}$. The projection of these subdivisions to the surface of the skin facilitates the localization of three motor points ${ }^{13}$.

The knowledge of the actions of muscle groups and of each muscle that constitutes them, as well as the

\footnotetext{
${ }^{1}$ School of Physical Therapy, Faculty of Health Sciences, Universidad de Talca, Talca, Chile

${ }^{2}$ Department of Statistics, Institute of Mathematics and Physics, Universidad de Talca, Talca, Chile

*Abstract accepted at International Society for Electrophysiology and Kinesiology, Brisbane, Australia, 19-21st July 2012.

Received: 06/23/2012 Revised: 12/03/2012 Accepted: 03/09/2013
} 
contribution of each NMC to the final action of the muscle, is fundamental for the effective rehabilitation of patients afflicted by neurological and muscle dysfunctions that impede basic movements, such as walking, jumping, sitting, and standing, as well as more demanding activities, such as sports ${ }^{14,15}$. These movements require the constant activation of stabilizing muscles in static and dynamic positions at the joints of the lower limbs. For example, the peroneus longus muscle stabilizes the frontal plane through the eversion action of the foot. The direct or indirect dysfunction of the peroneus longus muscle requires a rehabilitation process that includes various interventions, such as proprioception, neuromuscular and strength training ${ }^{16}$, neuromuscular electric stimulation (NMES) ${ }^{17}$, functional electric stimulation $(\mathrm{FES})^{18}$, and implantable stimulators of the fibular nerve ${ }^{19}$, among others. Interventions based on electrical principles take advantage of the physiological characteristics of muscles and nerves to generate therapeutic effects. One of these characteristics is the motor threshold (MT), which is defined as the minimum intensity at which a visible and palpable contraction of the muscle is obtained ${ }^{20}$. The MT varies between muscles and subjects and is used as a reference for localizing motor points.

Previous electromyographic (EMG) studies have demonstrated selective NMC activation in animals and humans ${ }^{1,15,21}$. It has not been demonstrated that these anatomic and physiologic characteristics influence the muscle functions that generate the movement of articulation. Triaxial accelerometry is one of the most frequently employed biomechanical tools, and it has been used in studies on walking and physical activity ${ }^{22}$. Triaxial accelerometers can be positioned on different areas of the body, allowing for the measurement of acceleration values in three axes of displacement. The aim of this study is to compare the NMCs of the peroneus longus muscle through the MT and acceleration of the foot. We hypothesized that the PI-NMC peroneus longus muscle has the lowest MT and that this same compartment contributes to greater acceleration of the foot on the $\mathrm{X}$ axes.

\section{Method}

This is a cross-sectional study with a nonprobabilistic sampling per group. The STROBE declaration was used to report the study ${ }^{23}$. The study was performed in the Biomechanical Laboratory of the School of Physical Therapy at the University of Talca, Chile. The environment was restricted to authorized personnel, and the illumination was adequate. The participants were recruited at the School of Physical Therapy during a four-month period starting on May 2011. Each individual was evaluated once.

\section{Participants}

The criteria used to calculate the size of the sample based on the mean and variance of the MT were as follows: (1) a confidence level of 95\%, (2) a precision value of $1,(3)$ a $12 \%$ variance from the MT average, and (4) a population of 220 students from the School of Physical Therapy from University of Talca. The sample size was calculated to be 37. A non-probabilistic sampling per group was conducted. Fifty young adult volunteers (18 to 24 years of age) were evaluated according to the inclusion criteria of a normal body mass index (BMI, $18.5-24.99 \mathrm{Kg}$ / $\mathrm{m}^{2}$ ). The exclusion criteria included the following: (1) BMI classification as overweight ( $\geq 25.00 \mathrm{Kg} / \mathrm{m}^{2}$ ) or obese $\left(\geq 30.00 \mathrm{Kg} / \mathrm{m}^{2}\right)$, (2) chronic neuromuscular and/or musculoskeletal disease, and (3) inferior extremity lesions in the six months preceding the evaluation. Figure 1 shows the design of the study. All of the subjects included in the study signed an informed consent form approved by the Bioethics Committee of the University of Talca (Folio 00058).

A total of 37 subjects, 23 women and 14 men, were analyzed in this study. The data for their age, $\mathrm{BMI}$, and leg perimeter were grouped by gender and had a normal distribution $(\mathrm{P}>0.05)$. The study participants' fibula lengths were subjected to logarithmic transformation to test the assumption of normality. Table 1 shows the basal demographic and anthropometric characteristics of the study subjects. There were no significant differences in terms of age $(\mathrm{P}=0.507)$, $\mathrm{BMI}(\mathrm{P}=0.714)$, or leg perimeter $(\mathrm{P}=0.082)$ between the genders. In contrast, the length of the fibula was significantly different between males and females $(\mathrm{P}=0.001)$.

\section{Procedure}

\section{Preparation and installation}

The weight and height of each subject were measured. The thickest region of the triceps surae was used to measure the perimeter of the leg. Finally, the length of the fibula from its apex to the most distal point of the lateral malleolus was measured.

Each participant was positioned on a stretcher in the supine decubitus position with support under the popliteal region. An electro-stimulation instrument was used (Myomed 932/serial 10396, 


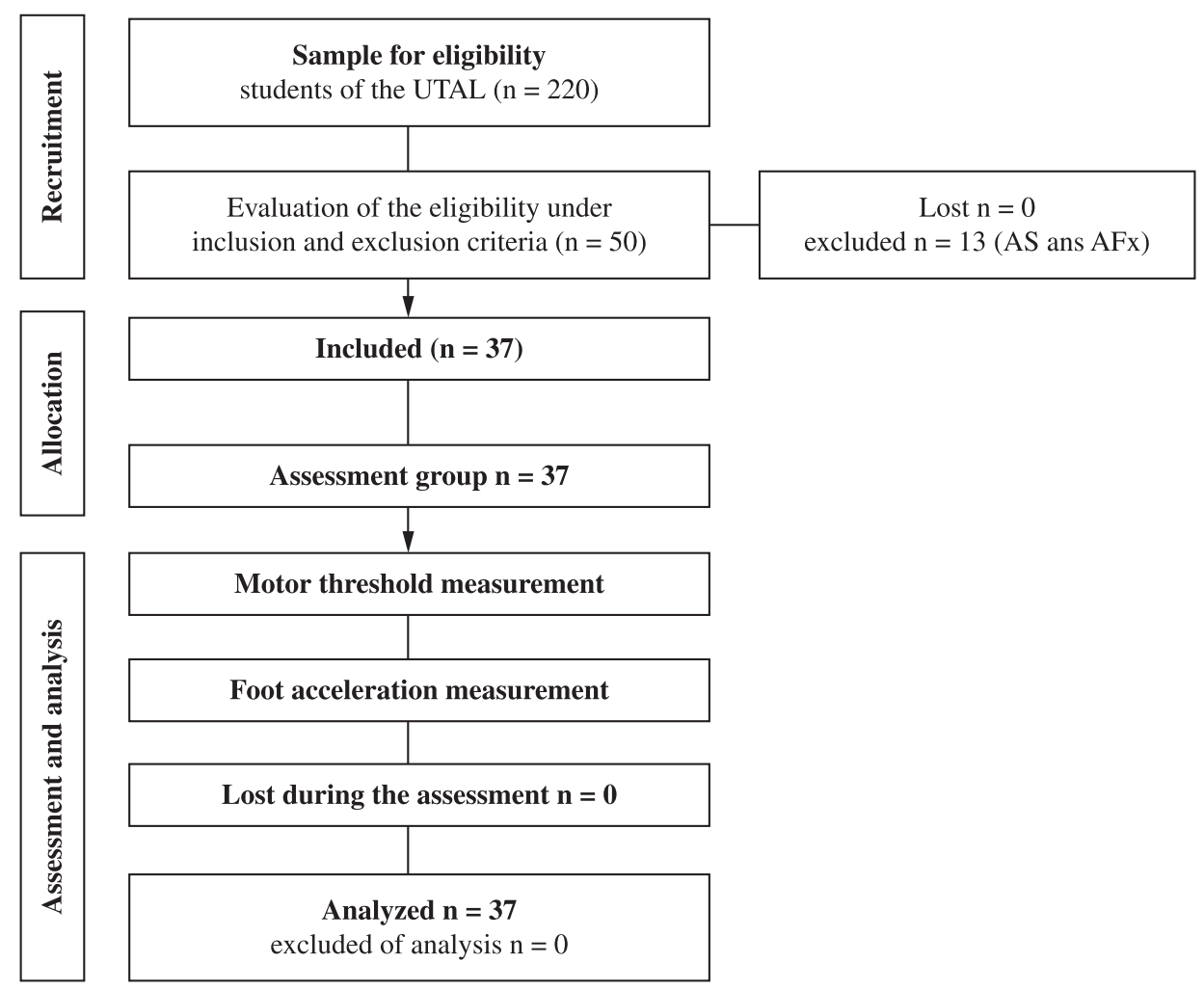

Figure 1. Study design. AS: ankle sprain; AFx: ankle fracture; UTAL: University of Talca (Universidad de Talca, in Spanish).

Table 1. Baseline characteristics of the sample population.

\begin{tabular}{llcc}
\hline \multicolumn{1}{c}{ Characteristics } & Gender & Mean (SD) & $P^{*}$ \\
Age $($ years $)$ & Female & $20.70(1.66)$ & 0.507 \\
& Male & $21.00(1.10)$ & \\
BMI $\left(\mathrm{K} / \mathrm{m}^{2}\right)$ & Female & $22.29(1.68)$ & 0.714 \\
& Male & $22.48(1.17)$ & \\
Leg Perimeter $(\mathrm{cm})$ & Female & $34.33(1.83)$ & 0.082 \\
& Male & $35.89(3.48)$ & \\
Fibula Length $(\mathrm{cm})$ & Female & $34.14(2.18)$ & 0.001 \\
& Male & $36.82(2.37)$ & \\
\hline
\end{tabular}

*T test for independent samples were considered significant when $\mathrm{p}<0.05$. SD: standard deviation.

Enraf Nonius Inc., PO Box 810, 2600 AV Delft, The Netherlands). The positive electrode was installed proximal to the medial malleolus of the tibia, and the negative electrode was prepared as the stimulation electrode (point). Finally, the triaxial accelerometer (ADXL335, Analog Devices Inc, One Technology Way, PO Box 9106, Norwood, Massachusetts 020629106, USA) was installed on the dorsal side of the first metatarsus right foot using adhesive tape (Figure 2).

All of the measurements were obtained in a single reading in the following two consecutive and uninterrupted stages (Figure 1): (1) MT measurement and (2) foot acceleration measurement. Both readings were obtained for the S-NMC, AI-NMC, and PINMC of each participant.

\section{Motor threshold measurement}

This study utilized information from previous investigations that described the localization of the motor points of the NMCs in the peroneus longus muscle (Figure 2), which was performed through a superficial projection based on a reference system of two coordinates for each compartment ${ }^{13}$. The following coordinates were used: S-NMC (41/4.9 mm), AI-NMC (59.9/6.2 mm), and PI-NMC (77.4/-3.1 mm). First, a reference axis between the apex of the head of the fibula and the lateral malleolus was established. Then, the first coordinate was used to indicate the distance from the head of the fibula along the reference axis. Finally, the second coordinate was used to indicate the perpendicular distance from the first coordinate, either anteriorly or posteriorly, according to positive or negative values, respectively.

The three compartments were stimulated with a basal intensity of $2 \mathrm{~mA}$, and the stimulus was progressively increased by $0.1 \mathrm{~mA}$ until the MT was reached. This value was then recorded in a results 


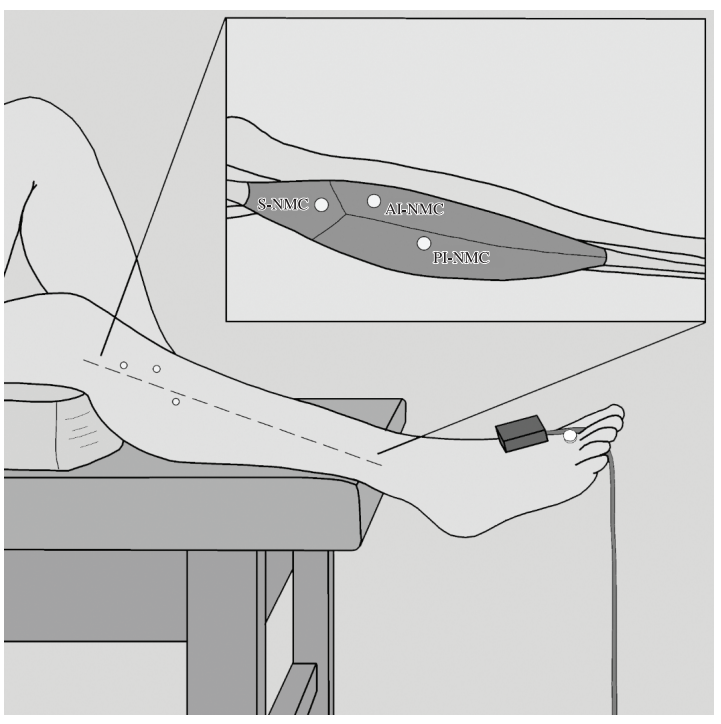

Figure 2. Procedure. The location of motor points in the NMCs and the installation of the accelerometer. S-NMC, superior neuromuscular compartment; AI-NMC, anteroinferior neuromuscular compartment; PI-NMC, posteroinferior neuromuscular compartment.

spreadsheet. The stimulation was performed with a monopolar square pulse duration of $200 \mu \mathrm{sec}$. Medium pulses ( $200 \mu \mathrm{sec})$ were utilized to ensure torque generation and to avoid muscle fatigue and nociceptor activation ${ }^{24-28}$.

\section{Foot acceleration measurement}

After MT measurement, the basal intensity was increased in a consecutive and uninterrupted manner in $0.1 \mathrm{~mA}$ intervals until an evident movement of the foot was obtained. The accelerometer was positioned so that the $\mathrm{X}$-axis corresponded to the medio-lateral direction, the $\mathrm{Y}$-axis to the anteroposterior direction, and the $\mathrm{Z}$-axis to the vertical direction. Due to the arrangement of the accelerometer presented above, the acceleration in axes $\mathrm{X}$ and $\mathrm{Y}$ largely represents the eversion movement of the foot. The acceleration axis $Z$ represents the movement of foot dorsal flexion. The acceleration values for the $\mathrm{X}$-, Y-, and Z-axes of each NMC were obtained and processed using the IGOR Pro 6.22A software (IGOR Pro 6.22A, WaveMetrics Inc., P.O. Box 2088, Lake Oswego, Oregon 97035, USA). After obtaining the records, we selected the spike on each axis acceleration, and the maximum amplitude was measured. The data were recorded on a data spreadsheet.

\section{Statistical analysis}

The data corresponding to age, BMI, leg perimeter, and fibula length were grouped by age and sex and analyzed for normality. Independent samples were analyzed using the t-test with a $\mathrm{P}$ value of 0.05 .

The MT variable was analyzed using a repeated measures analysis of variance of an intra-subject factor, the MT, which was obtained after the stimulation of each NMC. Three post-stimulation repetitions of this measurement were obtained per subject. The acceleration variable was analyzed with a repeated measures analysis of variance of two intra-subject factors, the NMCs and the axes, as well as the interaction among these parameters. The foot acceleration was measured in three axes (X, Y, and $\mathrm{Z}$ ) after the stimulation of each NMC (AI-NMC, PI$\mathrm{NMC}$, and S-NM), and nine repeated measurements were obtained per subject.

Both variables were subjected to tests for homogeneity of variance and Mauchly sphericity, considering a $\mathrm{P}$ value of 0.05 to be significant. For the analysis of variance, intra-subject tests and univariate and multivariate approximations with a $\mathrm{P}$ value of 0.05 were performed. For multiple comparisons by pairs, the Bonferroni post-hoc correction was used. The software used for these analyses was SPSS 14.0 (SPSS 14.0, SPSS Inc., 233 South Wacker Drive, Chicago, Illinois 60606-6412, USA).

\section{Results}

\section{Motor threshold}

Table 2 shows the average MT for each NMC. A repeated measures analysis of variance of an intrasubject factor was used. The variance of the NMC factor was homogeneous $(\mathrm{P}>0.05)$, and its sphericity was assumed $(\mathrm{P}=0.556)$. There were no significant differences in the test for univariate approximation for intra-subject effects, and there were no significant differences between the compartments $(\mathrm{F}=2.635$; $\mathrm{P}=0.079)$. Table 2 presents a comparison of the MT between compartments using the Bonferroni post-hoc correction. There were no significant differences for the MT between NMCs $(\mathrm{P}>0.05)$.

\section{Foot acceleration}

Table 3 presents the average acceleration of the axes for each neuromuscular compartment. A repeated measures analysis of variance for two intra-subject factors was used. The variance was homogeneous for all factors $(\mathrm{P}>0.05)$. Sphericity was assumed for all NMCs $(\mathrm{P}=0.206)$ and for the axes of acceleration $(\mathrm{P}=0.713)$. The test for univariate approximation did not reveal a significant difference for intra-subject effects between compartments $(\mathrm{F}=1.811, \mathrm{P}=0.171)$. 
Table 2. Comparison of motor threshold between neuromuscular compartments.

\begin{tabular}{cccc}
\hline Compartment & Mean MT (SD) & NMC/NMC & Difference (CI 95\%) \\
AI & $14.53(3.23)$ & AI-NMC/PI-NMC & $0.711(0.126-1.547)$ \\
PI & $14.31(2.08)$ & AI-NMC/S-NMC & $0.368(0.410-1.145)$ \\
S & $14.26(2.78)$ & PI-NMC/S-NMC & $0.343(1.057-0.371)$ \\
\hline
\end{tabular}

$* \mathrm{P}<0.05$, post-hoc test Bonferroni correction for multiple comparisons by pairs (NMC/NMC). MT: motor threshold (mA); SD: standard deviation; NMC: neuromuscular compartment; AI: anteroinferior; PI: posteroinferior; S: superior.

Table 3. Comparison of acceleration between the axes in each neuromuscular compartment.

\begin{tabular}{ccccc}
\hline Compartment & Axis & Mean A (SD) & Axi-Axi & Difference (CI 95\%) \\
AI & X & $0.506(0.189)$ & X-Y & $0.142(0.037-0.248)^{*}$ \\
& Y & $0.364(0.162)$ & X-Z & $0.303(0.206-0.400)^{*}$ \\
Z & $0.203(0.162)$ & Y-Z & $0.161(0.071-0.251)^{*}$ \\
PI & X & $0.614(0.253)$ & X-Y & $0.268(0.132-0.404)^{*}$ \\
& Y & $0.346(0.196)$ & X-Z & $0.378(0.257-0.499)^{*}$ \\
& Z & $0.236(0.171)$ & Y-Z & $0.110(0.023-0.197)^{*}$ \\
S & $0.484(0.211)$ & $X-Y$ & $0.052(0.051-0.155)$ \\
& Y & $0.432(0.162)$ & $X-Z$ & $0.214(0.114-0.314)^{*}$ \\
& Z & $0.270(0.152)$ & Y-Z & $0.162(0.070-0.254)^{*}$ \\
\hline
\end{tabular}

* $\mathrm{P}<0.05$, post-hoc test Bonferroni correction for multiple comparisons by pairs of axes in each compartment. SD: standard deviation; A: acceleration; AI: anteroinferior; PI: posteroinferior; S: superior.

In contrast, significant differences in the acceleration axes were found $(\mathrm{F}=56.233, \mathrm{P}=0,000)$. Sphericity was not assumed for the NMC-axis interaction $(\mathrm{P}=0.003)$. Because the sphericity hypothesis was rejected, and the size of the sample $(\mathrm{n}=37)$ was greater than $10+\mathrm{k}(\mathrm{k}, \text { number of repeated measurements })^{29}$, a multivariate approximation for intra-subject effects was used. No significant differences were found in the effects of the NMC-axis interactions $(\mathrm{F}=2.553$, $\mathrm{P}=0.057$ ). Table 3 presents a comparison of the acceleration between the axes in each of the NMCs after a Bonferroni post-hoc correction. There were significant differences between the acceleration axes for each compartment, except for the S-NMC, in which no significant difference between the $\mathrm{X}$ - and $\mathrm{Y}$-axes was detected $(\mathrm{P}=0.063)$.

\section{- Discussion}

This study did not detect differences related to age, BMI, or leg diameter between men and women. These results indicate that the basal characteristics were homogeneous between the subjects, thus permitting the analysis of acceleration and MT without considering the gender of the subjects. Although the length of the fibula presented significant differences $(\mathrm{P}=0.001)$ between genders, this was not taken into account. This factor was not taken into account because in the study by Méndez et al. ${ }^{13}$, which was used as a topographic reference for this study, a differential analysis between men and women was not reported, thus precluding any differentiation between subsequent measurements.

No significant differences in the MT were found between the NMCs $(\mathrm{F}=2.635, \mathrm{P}=0.079)$, suggesting that the bioelectrical behavior of each compartment is the same. This result can be explained by the proximity of the motor points. As such, stimulation may result in the depolarization of the muscle fibers of the NMC, as well as of the neighboring compartments. Several factors should be taken into account when using the motor point and the MT as a reference for muscle stimulation. The motor point is defined as the location at which the nerve enters the muscle, which is usually immediately proximal to the initial ramification of the nerve ${ }^{30}$. In addition, the motor point is the skin surface at which the maximal mechanical response is elicited with the minimum applied current. However, English et al. ${ }^{14}$ described a more complex organization of the studied region. They indicated that the nerve or primary motor branch continues its path inside the muscle, dividing into two or more secondary branches that reach the $\mathrm{NMCs}^{14,31}$. Lim et al. ${ }^{32}$ confirmed the presence of secondary 
motor branches. These authors explained that the distribution of the intra-muscular nervous branches is affected by the presence of aponeurosis and the muscle-tendon junction. The nerves that penetrate the muscle and reach these structures divide into secondary nervous branches that cross to each side of the tendon ${ }^{32}$.

The motor points used in this study were superficial projections of the intrafascicular secondary branches. Thus, they can be defined as secondary motor points. Consequently, they are not comparable to the motor points used in NMES and FES, raising the possibility that these points may be superposed or in a close topographical relationship in small- or medium-sized muscles. In contrast, major muscles, such as the rectus femoris $^{21}$, medial gastrocnemius ${ }^{7}$, and trapezius ${ }^{1}$, among others, have NMCs with distant motor points.

The intrafascicular motor branches subdivide into numerous branches that join the muscle fiber sarcolemma, specifically in the area corresponding to the neuromuscular junction or motor plate ${ }^{33}$. Consequently, the stimulation of the motor points of each NMC affects the entire area of the motor plate. In the same manner, a group of motor plates delimits an area that corresponds to the highest level of electrical activity in a muscle ${ }^{34,35}$. The motor plates and the innervation zones are distal to the primary motor branch ramification ${ }^{3}$. The innervation zone in a small muscle can include more than one motor point, thus making it impossible to detect the MT of each NMC or to establish adequate electrical parameters for NMES or FES. Watanabe et al. ${ }^{21}$ studied the innervation zones and the NMCs of the rectus femoris in humans using multi-channel surface EMG. They found that this muscle possesses two NMCs, proximal and distal, each with an innervation zone.

In this study, we found differences between the axes of acceleration within each NMC ( $\mathrm{F}=56.233$, $\mathrm{P}=0.000$ ).

The AI-NMC and PI-NMC presented significant differences in all of the acceleration axes, with the highest average acceleration in the X-axis (Mean 0.614 ; standard deviation 0.253 ) of the PI-NMC. This observation explains why the electrical stimulation of the PI-NMC in the peroneus longus muscle resulted in a major contribution to foot acceleration along the $\mathrm{X}$-axis, corresponding to the medial-lateral displacement that is part of the eversion movement of the foot. These results are related to the anatomical characteristics of this compartment, which is posterior to the AI-NMC and distal to the S-NMC.

The S-NMC acceleration presented no significant differences in the $\mathrm{X}$ - or $\mathrm{Y}$-axes. This finding corresponds to the anatomical position of the S-NMC, which is located above the AI-NMC and PI-NMC. Upon stimulation, the S-NMC exerts traction through via the connective tissues that are connected to the underlying compartments (intramuscular septum) ${ }^{12}$. These compartments accelerate the foot along the $\mathrm{X}$ - and $\mathrm{Y}$-axes with comparable intensity.

The AI-NMC behaves similarly to the other compartments, but the resulting acceleration in the $\mathrm{X}$ axis was smaller than that caused by the PI-NMC.

These results support the findings of other authors, who have shown that some muscles of mammals are compartmentalized. Wolf et al. ${ }^{15}$ studied the selective activation of the NMCs in the human medial gastrocnemius. Similarly, Watanabe et al. ${ }^{21}$ used multiple tests to show the differential activation of the proximal and distal NMCs in the rectus femoris. Holtermann et al. ${ }^{1}$ also observed a selective activation of the superior, medial, and inferior NMCs in the trapezius muscle. All of these studies used surface EMG to evaluate the NMCs in different functional tests. In contrast, the present study evaluated foot acceleration after electric stimulation by triaxial accelerometry, a feasible tool for evaluating differences in NMC muscle activation along different activation directions.

The knowledge of NMCs and their actions on articular segments could be used as a new approach when designing the motor therapy of a patient. Specifically, it should be considered that a muscle does not act as a unit but rather as a complex of several subunits that coordinately influence the joint segment. Furthermore, these data may be used in the design of external and implantable stimulators, for example, in the sequelae paretic segments of stroke patients. Finally, future investigations should focus on the following: (1) identifying the intrafascicular motor points of the NMCs in diverse muscle groups; (2) identifying the existence of one or multiple innervation zones; (3) establishing whether the NMCs possess specific functional roles; and (5) investigating the behavior of the NMCs in different disorders. For these purposes, multi-channel surface EMG could potentially allow for selective evaluation of the NMCs.

\section{Limitations}

All of the measurements were performed on students from the Kinesiology School of Talca University, and all of the investigators in this study are employed at this institution. Thus, a measurement bias may be possible. Additionally, the differences in fibula length and the localization of the motor 
points between genders were not taken into account. Future investigations should determine the effects of gender on these differences. Teepker et al. ${ }^{36}$ noted that menstruating women had a lower pain threshold for electrical stimuli. In the present study, we did not consider the presence of menstruation cycle of women who were evaluated, which could have influenced the results ${ }^{36}$.

\section{- Conclusion}

The NMCs of the peroneus longus presented the same MT. The PI-NMC contributed the most to foot acceleration along the $\mathrm{X}$-axis, corresponding to the direction of the medial-lateral displacement that is part of the eversion movement of the foot.

\section{- Acknowledgments}

This study was supported by the Research Direction (Project VAC 600 538) and the School of Physical Therapy, University of Talca, Talca, Chile.

\section{References}

1. Holtermann A, Roeleveld K, Mork PJ, Grönlund C, Karlsson JS, Andersen LL, et al. Selective activation of neuromuscular compartments within the human trapezius muscle. J Electromyogr Kinesiol. 2009;19(5):896902. PMid:18585928. http://dx.doi.org/10.1016/j. jelekin.2008.04.016

2. Ravichandiran M, Ravichandiran N, Ravichandiran K, McKee NH, Richardson D, Oliver M, et al. Neuromuscular partitioning in the extensor carpi radialis longus and brevis based on intramuscular nerve distribution patterns: A three-dimensional modeling study. Clin Anat. 2012 Apr;25(3):366-72. http://dx.doi.org/10.1002/ca.21246

3. Bowden JL, McNulty PA. Mapping the motor point in the human tibialis anterior muscle. Clin Neurophysiol. 2012;123(2):386-392. PMid:21802984. http://dx.doi. org/10.1016/j.clinph.2011.06.016

4. Galvas PE, Gonyea WJ. Motor-end-plate and nerve distribution in a histochemically compartmentalized pennate muscle in the cat. Am J Anat. 1980;159(2):147-156. PMid:7446445. http://dx.doi.org/10.1002/aja.1001590203

5. Liu J, Kumar VP, Lau HK, Pereira BP, Shen Y, Pho RW. Neuromuscular compartments in the long head of triceps: a morphological study in rabbits. Muscle Nerve. 1997;20(7):897-899. http://dx.doi. org/10.1002/(SICI)1097-4598(199707)20:7<897::AIDMUS18>3.0.CO;2-P

6. Harris AJ, Duxson MJ, Butler JE, Hodges PW, Taylor JL, Gandevia SC. Muscle fiber and motor unit behavior in the longest human skeletal muscle. J Neurosci. 2005;25(37):8528-8533. PMid:16162934. http://dx.doi. org/10.1523/JNEUROSCI.0923-05.2005
7. Kim MW, Kim JH, Yang YJ, Ko YJ. Anatomic localization of motor points in gastrocnemius and soleus muscles. Am J Phys Med Rehabil. 2005;84(9):680-683. PMid:16141745. http://dx.doi.org/10.1097/01.phm.0000176341.85398.a9

8. Bakkum BW, Russell K, Adamcryck T, Keyes M. Gross anatomic evidence of partitioning in the human fibularis longus and brevis muscles. Clin Anat. 1996;9(6):381-385. http://dx.doi.org/10.1002/ (SICI)1098-2353(1996)9:6<381::AID-CA4>3.0.CO;2-E

9. Monti RJ, Roy RR, Edgerton VR. Role of motor unit structure in defining function. Muscle Nerve. 2001;24(7):848-866. PMid:11410913. http://dx.doi. org/10.1002/mus.1083

10. Letbetter WD. Influence of intramuscular nerve branching on motor unit organization in medial gastrocnemius muscle. Anat Rec. 1974;178:402-414.

11. English AW, Letbetter WD. Anatomy and innervation patterns of cat lateral gastrocnemius and plantaris muscles. Am J Anat. 1982;164(1):67-77. PMid:7102574. http:// dx.doi.org/10.1002/aja.1001640107

12. El Gharbawy RM, Skandalakis LJ, Skandalakis JE. Protective mechanisms of the common fibular nerve in and around the fibular tunnel: a new concept. Clin Anat. 2009;22(6):738-746. PMid:19644970. http://dx.doi. org/10.1002/ca.20844

13. Méndez RG, Coronado GR, Suazo GI. Anatomical Study of the Fibularis Longus Muscle Motor Points and Electrical Stimulation Therapy Application. Int J Morphol. 2009;27(3):699-703.

14. English AW, Wolf SL, Segal RL. Compartmentalization of muscles and their motor nuclei: the partitioning hypothesis. Phys Ther. 1993;73(12):857-867. PMid:8248294.

15. WolfSL, SegalRL,EnglishAW.Task-orientedEMGactivity recorded from partitions in human lateral gastrocnemius muscle. J Electromyogr Kinesiol. 1993;3(2):87-94. http:// dx.doi.org/10.1016/1050-6411(93)90003-F

16. Holmes A, Delahunt E. Treatment of common deficits associated with chronic ankle instability. Sports Med. 2009;39(3):207-224. PMid:19290676. http://dx.doi. org/10.2165/00007256-200939030-00003

17. Botter A, Oprandi G, Lanfranco F, Allasia S, Maffiuletti NA, Minetto MA. Atlas of the muscle motor points for the lower limb: implications for electrical stimulation procedures and electrode positioning. Eur J Appl Physiol. 2011;111(10):2461-2471. PMid:21796408. http://dx.doi. org/10.1007/s00421-011-2093-y

18. Peckham PH, Knutson JS. Functional electrical stimulation for neuromuscular applications. Annu Rev Biomed Eng. 2005;7:327-360. PMid:16004574. http://dx.doi. org/10.1146/annurev.bioeng.6.040803.140103

19. Kottink AI, Hermens HJ, Nene AV, Tenniglo MJ, GroothuisOudshoorn CG, IJzerman MJ. Therapeutic effect of an implantable peroneal nerve stimulator in subjects with chronic stroke and footdrop: a randomized controlled trial. Phys Ther. 2008;88(4):437-448. PMid:18218825. http:// dx.doi.org/10.2522/ptj.20070035

20. Chipchase LS, Schabrun SM, Hodges PW. Peripheral electrical stimulation to induce cortical plasticity: a systematic review of stimulus parameters. Clin 
Neurophysiol. 2011;122(3):456-463. PMid:20739217. http://dx.doi.org/10.1016/j.clinph.2010.07.025

21. Watanabe K, Kouzaki M, Moritani T. Task-dependent spatial distribution of neural activation pattern in human rectus femoris muscle. J Electromyogr Kinesiol. 2012 Apr;22(2):251-8. http://dx.doi.org/10.1016/j. jelekin.2011.11.004

22. Godfrey A, Conway R, Meagher D, OLaighin G. Direct measurement of human movement by accelerometry. Med Eng Phys. 2008;30(10):1364-1386. PMid:18996729. http://dx.doi.org/10.1016/j.medengphy.2008.09.005

23. Von Elm E, Altman DG, Egger M, Pocock SJ, Gøtzsche PC, Vandenbroucke JP; STROBE Initiative. The Strengthening the Reporting of Observational Studies in Epidemiology (STROBE) statement: guidelines for reporting observational studies. J Clin Epidemiol. 2008;61(4):344-349. PMid:18313558. http://dx.doi. org/10.1016/j.jclinepi.2007.11.008

24. Kantor G, Alon G, Ho HS. The effects of selected stimulus waveforms on pulse and phase characteristics at sensory and motor thresholds. Phys Ther. 1994;74(10):951-962. PMid:8090846.

25. Kesar T, Binder-Macleod S. Effect of frequency and pulse duration on human muscle fatigue during repetitive electrical stimulation. Exp Physiol. 2006;91(6):967976. PMid:16873456. http://dx.doi.org/10.1113/ expphysiol.2006.033886

26. Scott WB, Causey JB, Marshall TL. Comparison of maximum tolerated muscle torques produced by 2 pulse durations. Phys Ther. 2009;89(8):851-857. PMid:19541774. http://dx.doi.org/10.2522/ptj.20080151

27. Gorgey AS, Black CD, Elder CP, Dudley GA. Effects of electrical stimulation parameters on fatigue in skeletal muscle. J Orthop Sports Phys Ther. 2009;39(9):684-692. PMid:19721215.

28. Salmons S. Adaptive change in electrically stimulated muscle: a framework for the design of clinical protocols. Muscle Nerve. 2009;40(6):918-935. PMid:19902542. http://dx.doi.org/10.1002/mus.21497

29. Atkinson G. Analysis of repeated measurements in physical therapy research. Phys Ther Sport. 2001;2:194208. http://dx.doi.org/10.1054/ptsp.2001.0071
30. Duchenne de Bolougne G. A Treatise on localized electrization, and its applications to pathology and therapeutics. Paris: J.B. Baillière; 1855.

31. Segal RL, Wolf SL, DeCamp MJ, Chopp MT, English AW. Anatomical partitioning of three multiarticular human muscles. Acta Anat (Basel). 1991;142(3):261-266. http:// dx.doi.org/10.1159/000147199

32. Lim AY, Pereira BP, Kumar VP, De Coninck C, Taki C, Baudet $\mathrm{J}$, et al. Intramuscular innervation of upper-limb skeletal muscles. Muscle Nerve. 2004;29(4):523-530. PMid:15052617. http://dx.doi.org/10.1002/mus.10565

33. Lichtman JW, Sanes JR. Watching the neuromuscular junction. J Neurocytol. 2003;32(58):767-775. PMid:15034266. http://dx.doi. org/10.1023/B:NEUR.0000020622.58471.37

34. Masuda T, Miyano H, Sadoyama T. The position of innervation zones in the biceps brachii investigated by surface electromyography. IEEE Trans Biomed Eng. 1985;32(1):36-42. PMid:3980027. http://dx.doi. org/10.1109/TBME.1985.325614

35. Barbero M, Gatti R, Lo Conte L, Macmillan F, Coutts F, Merletti R. Reliability of surface EMG matrix in locating the innervation zone of upper trapezius muscle. J Electromyogr Kinesiol. 2011;21(5):827833. PMid:21752668. http://dx.doi.org/10.1016/j. jelekin.2011.05.013

36. Teepker M, Peters M, Vedder H, Schepelmann K, Lautenbacher S. Menstrual variation in experimental pain: correlation with gonadal hormones. Neuropsychobiology. 2010;61(3):131-140. PMid:20110738. http://dx.doi org/10.1159/000279303

\section{Correspondence}

\section{Guillermo A. Méndez}

Universidad de Talca

Faculty of Health Sciences

School of Physical Therapy

Av. Lircay S/N,

Talca, Chile

e-mail: gmendez@utalca.cl 